Archives de sciences sociales des religions

176 | octobre-décembre 2016

Bulletin Bibliographique

\title{
François Raviez (éd.), Poétique du spirituel
}

Arras, Artois Presse Université, 2016, 184 p.

\section{Daniel Vidal}

\section{(2) OpenEdition}

\section{Journals}

Édition électronique

URL : http://journals.openedition.org/assr/28330

DOI : $10.4000 /$ assr.28330

ISSN : $1777-5825$

Éditeur

Éditions de l'EHESS

Édition imprimée

Date de publication : 31 décembre 2016

Pagination : 377

ISSN : 0335-5985

Référence électronique

Daniel Vidal, «François Raviez (éd.), Poétique du spirituel », Archives de sciences sociales des religions [En ligne], 176 | octobre-décembre 2016, mis en ligne le 20 juillet 2017, consulté le 24 septembre 2020. URL : http://journals.openedition.org/assr/28330 ; DOI : https://doi.org/10.4000/assr.28330

Ce document a été généré automatiquement le 24 septembre 2020

(c) Archives de sciences sociales des religions 


\title{
François Raviez (éd.), Poétique du spirituel
}

Arras, Artois Presse Université, 2016, 184 p.

\author{
Daniel Vidal
}

\section{RÉFÉRENCE}

François Raviez (éd.), Poétique du spirituel, Arras, Artois Presse Université, 2016, 184 p.

De longue date fut analysée la relation du poétique à la spiritualité, du langage à l'expérience mystique, du verbe à la diction de «l'ineffable »- du Cantique des Cantiques à son chant. Rappeler d'emblée l'œuvre de Michel de Certeau permet de centrer cette relation dans le seul espace de sens qui l'autorise : l'espace du sujet en sa parole. Espace où le poétique constitue à la fois l'art souverain de cette parole, sa construction, son architecture, et donc la "méthode» qui doit gouverner l'énoncé du verbe - et le dépassement permanent de cette méthode par le vouloir-dire du "spirituel », ce sujet en sa singularité et sa subjectivité. C'est en cette revendication de double contrainte que l'ouvrage dirigé par François Raviez peut trouver sa légitimité. Car il n'était pas immédiatement évident de réunir études bouddhiques, médiévales et de littérature moderne sous le même questionnement du rapport au poétique, si celui-ci ne pouvait s'entendre comme à la fois méthode de discours et performativité du verbe, assujettissement à une forme et liberté d'une parole saisie en sa propre émotion, art pleinement maîtrisé, et la formule chaque fois irrécusable qui s'y déploie. Sans doute chaque expérience spirituelle répond-elle différemment à cette double condition, d'« art » et de verbe singulier, privilégiant l'un ou autre en fonction de son inscription historique propre, la langue poétique trouvant toujours le site scripturaire qui peut en assurer l'accomplissement et la portée. Les travaux de Danièle Masset sur les stances des premiers moines bouddhistes et les recherches de Katia Buffetrille sur la littérature tibétaine du pèlerinage attestent l'importance capitale d'une parole spirituelle tissée dans le cadre strict d'un ensemble de méthodes d'écriture qui en autorise d'expression. 
Certes, telle spiritualité convoque des éléments fondamentaux de toute "mystique » : extinction de soi, renoncement, neutralisation du « karma », cette « force terrible » du destin, "source potentielle de souffrances", où l'on retrouve des configurations communes à d'autres expériences en spiritualité. Mais, ici, selon un lexique, des traits de style, des ensembles d'expressions, des schémas de visions du monde, à partir desquels ces stances poétiques s'organisent et se déroulent. Plus que de "parole poétique ", il s'agirait alors de "mise en scène ", ce qui loin d'affaiblir l'opération mystique, lui donnerait rigueur et exemplarité. Un «jeu» se développe entre «la récurrence des formules stéréotypées ", qui peut aller jusqu'à la récitation intégrale des paroles de Bouddha, et "l'expérience intime des moines », qui en est informée autant qu'elle les informe. Un échange de même nature s'opère entre la vision intérieure spirituelle et les impératifs littéraires stéréotypés, dans la littérature de pèlerinage, cette "appropriation symbolique » d'un espace. Qui métamorphose tels monts en «montagnes sacrées». Dans ce mouvement de spiritualisation d'un lieu se mobilisent des référents "littéraires stéréotypés ", en même temps qu'une "vision intérieure " mystique. Le paysage extérieur se transforme en paysage intérieur : c'est à ce prix que l'espace est «soumis ", par une parole, un texte, une pensée, tissus de merveilleux, cet autre nom, ici, du poétique.

2 Et du merveilleux, du surnaturel, le Moyen-Âge est saison d'excellence, dont témoignent les recherches de Myriam White-Le Goff et Mireille Demaules. Sans doute faut-il repenser ces catégories descriptives sous le sceau du poétique, et comme leur matrice propre. Si la «fable mystique » témoigne de l'impossibilité de dire le divin, par définition ineffable, autrement qu'en termes d'absence et de négation, alors le merveilleux ouvre un registre d'images et de paroles au cœur même de cette négativité. Mais on voit que du même coup une spiritualité "non dogmatique » se met en place, qui autorise l'expression d'une subjectivité singulière, où les symboles se multiplient et se transforment (l'exemple du mythe du Graal est ici éloquent : d'objet celtique, le voilà transformé en réceptacle du sang christique). Ainsi se fonde une économie spirituelle attentive "à l'inouï et l'invraisemblable», par quoi le réel est le lieu même de l'impossible. Si l'on passe ainsi « de la féerie païenne au merveilleux chrétien », et si ce merveilleux lui-même est injecté dans les Écritures par le détour d'écrits apocryphes, ce travail au centre du symbolique est d'abord œuvre, précisément, d'écriture. Par quoi le « réel », site de transcendance, est désormais expérience de l'altérité. L'autre est ce qui est outre. "De dérive en dérive», le merveilleux n'invente pas seulement de nouvelles formes d'êtres et de choses, de situations et d'évènements - il décide d'une "stylistique de la joie », et d'une créativité fiévreuse. Le sujet de cet éblouissement de la parole peut alors se penser "dans son individualité », et l'imaginaire qu'il convoque " poussé jusqu'à ses limites ». L'un ne va pas sans l'autre.

3 Il est sans doute quelque «merveilleux » dans le pathétique voyage de Pierre Loti en Terre Sainte, mais qui se résorbe en une hallucination des lieux et des temporalités, des figures et des actes sacrificiels. Raviez peut à bon droit parler de "dramaturgie ", qui scande les attentes et les défaillances de l'écrivain. Et en donne le cadre. Là tout n'est que désordre et déception, violence et pauvreté de signes et de gestes. Au plus loin semble-t-il d'une poétique et d'une spiritualité, quand tout se referme sur un moi exhibé en inquiétude. Trop enchaîné à un réalisme de convention pour accéder à un réel autrement plus riche en enchantements. D'autres voyages « littéraires » s'offrent cependant comme itinéraires de parfaite spiritualité. Mais aussi bien la route qui y 
mène. La voie est chemin de spiritualité, et raison de sa poétique. Elle est « désir plus qu'assouvissement». Pour Roger Frison-Roche, pour Théodore Monod, Sahariens inassouvis, le désert est cet «absolu » qui exhausse l'homme. Où s'opère enfin, pour Ernest Psichari, "le corps à corps de l'homme avec lui-même ». Retour vers le sujet, principe et fin de la quête mystique ? Cela peut en effet se dire à même le corps où toute blessure fait aussitôt symbole. Dans Sainte Lydwine de Schiedam, Joris-Karl Huysmans réactive, selon Raviez, tout un merveilleux de plaies et de déchéances corporelles, en une «mystique de substitution » : l'innocent souffre pour le coupable et le rachète. Économie de la perte de soi pour le salut de l'autre. Le langage du corps fonctionne ainsi comme agent miraculeux. De cette chute au plus profond du corps en ses ténèbres, à cette « hauteur du langage » que Pierre-Jean Jouve sollicite pour dire le sacré, le saut est à proportion de l'enjeu. Dorothée Cooche-Catoen, à propos du poète, rappelle ce qu'en dit Serge Mettinger. Le poétique est très exactement «ce qui permet de surmonter l'intransitivité des instants de l'âme ». Il est la dynamique même qui extrait la "substance spirituelle» du langage par ce que l'auteur nomme «la vertu incantatoire des mots». Ainsi se nouent, dans l'expérience spirituelle, l'art poétique porté à la plus fine pointe de sa raison, et la "présence invisible » d'un dieu qui n'est que d'être absent. 